\title{
El Buen Vivir como alternativa al desarrollo. Algunas reflexiones económicas y no tan económicas
}

\author{
Alberto Acosta ${ }^{1}$ \\ Profesor e investigador de la FLACSO-Ecuador \\ aacosta@flacso.edu.ec
}

Recibido: 13-05-2014

Aceptado: $08-05-2015$

\section{Resumen}

El articulo comienza por hacer una critica de la construcción histórica de los conceptos de "progreso" y de "desarrollo" que han querido justificar las propuestas y promesas de bienestar, colonialistas y capitalistas, impulsadas en realidad desde hace siglos. Estas promesas no se han cumplido para la mayoría de la humanidad. Y todo esto ha dado lugar a un debate creciente sobre las "alternativas al desarrollo" y el "cambio civilizatorio". Dentro de este debate y desde los pueblos originarios de los Andes y el Amazonas surge la propuesta de Sumak Kawsay o Buen Vivir que llega a ser reconocida dentro de las Constituciones del Ecuador y Bolivia. Se trata de valores, experiencias y prácticas provenientes de la vida indgena comunitaria, que se centra en la armonía entre los individuos viviendo comunidad, entre los pueblos y de todos con la naturaleza. Por ejemplo, en la Constitución del Ecuador se reconoce a la Naturaleza como sujeto de derechos. En esta misma linea se plantea una transición hacia una economía solidaria y sustentable, que incluye el decrecimiento del extractivismo, y el auto-centramiento en las políticas locales y participativas. Los Buenos Convivires, en tanto vivencia mas que un concepto, nos abren la puerta para construir un mundo donde quepan todos los mundos, en los que todos los seres humanos puedan vivir con dignidad.

Palabras clave: Sumak Kawsay; desarrollo; practicas comunitarias; indigenismo.

${ }^{1}$ Economista ecuatoriano. Profesor e investigador de la FLACSO-Ecuador. Profesor honorario de la universidad Ricardo Palma, Lima Ex-ministro de Energía y Minas. Ex-presidente de la Asamblea Constituyente. Ex-candidato a la Presidencia de la República.

NotA: Este texto recoge reflexiones de varios trabajos anteriores del autor, entre otros del libro El Buen Vivir - Sumak Kawsay, una oportunidad para imaginar otros mundos, Icaria, Barcelona (2013), en versiones actualizadas ha sido publicado en francés (Utopia, 2014) y en alemán (Oekom Verlag, 2015). 


\title{
The Buen Vivir as an Alternative to Development. Some Economic and non-so Economic Considerations
}

\begin{abstract}
The article begins with a critique of the historical construction of concepts such as "progress" and "development" that have been used for centuries to justify colonialist and capitalist proposals and promises of welfare. For a large part of mankind, these promises have not been fulfilled. Therefore, a growing debate on "alternative development" and "civilizational change" has emerged. Within this debate, the indigenous peoples of the Andes and the Amazon have put forward another proposal: the "good living" or Sumak Kawsay, that has been included in the Constitutions of Ecuador and Bolivia. Good Living is about values, experiences and practices from indigenous community, and it focuses on harmony among individuals living in the community, among peoples, and among them and nature. For example, in the Constitution of Ecuador Nature is a subject of rights. In the same vein, the Constitution intends a transition towards caring and sustainable economy, which includes the decrease of extractive economy and focuses on local and participatory policies. "Good living" needs to be understood more as an experience than as a mere concept. Consequently it makes possible to build a world in which all worlds can fit, where all human beings can live with dignity.
\end{abstract}

Keywords: Sumak Kawsay; Development; Community Practices; Indigeneity.

\section{Referencia normalizada}

Acosta, Alberto (2015): "El Buen Vivir como alternativa al desarrollo. Algunas reflexiones económicas y no tan económicas", Política y Sociedad, 52 (2), pp. 299-330.

Sumario: 1. El desarrollo, un fantasma inalcanzable. 2. El progreso, antesala del desarrollo. 3. El desarrollo, sus alternativas y sus limitaciones. 4. El Buen Vivir, propuesta de cambio civilizatorio desde la periferia del mundo. 5. Hacia un reencuentro con la Naturaleza. 6. Los elementos de una economía solidaria y sustentable. 7. Al rescate o construcción de otras lógicas económicas. 8. Un penúltimo punto: construcción paciente, no improvisación irresponsable. 9. Bibliografía. 
Los mundos nuevos deben ser vividos antes de ser explicados.

Alejo Carpentier

América Latina ha sido una de las regiones desde donde han surgido potentes voces críticas en contra del orden mundial impuesto, como una suerte de ejercicio permanente de resistencia. En la actualidad este esfuerzo se profundiza con un interesante proceso de reinterpretación de los orígenes indígenas de esta región. Así se mantiene y recupera una tradición histórica de críticas y cuestionamientos que fueron elaborados y presentados desde hace mucho tiempo atrás, pero que quedaron rezagados y amenazados de olvido. Y lo que es más interesante aún, hoy afloran otras concepciones marginadas del discurso y las prácticas convencionales, sobre todo originarias, propias de los pueblos y nacionalidades ancestrales del Abya Yala (Nuestra América, diría José Martí), así como también provenientes de otras regiones de la Tierra.

En efecto, estas propuestas se expresan concretamente en las constituciones de Ecuador (2008) y Bolivia (2009); en el primer caso es el Buen Vivir o Sumak Kawsay (en kichwa), y en el segundo, en particular el Vivir Bien o suma qamaña (en aymara) y también Sumak Kawsay (en quechua). Existen nociones similares (mas no idénticamente iguales) en otros pueblos indígenas, como los mapuche (Chile), los guaraní (Bolivia y Paraguay), los kuna (Panamá), los achuar (Amazonia ecuatoriana), pero también en la tradición Maya (Guatemala), en Chiapas (México), entre otros.

A más de estas visiones del Abya-Yala hay otras muchas aproximaciones a pensamientos filosóficos de alguna manera emparentados con la búsqueda del Buen Vivir desde visiones filosóficas incluyentes en diversas partes del planeta. El Buen Vivir, en tanto cultura de la vida, con diversos nombres y variedades, ha sido conocido y practicado en distintos períodos en las diferentes regiones de la Madre Tierra, como podría ser el Ubuntu en África o el Svadeshi, el Swaraj y el Apargrama en la India. Aunque se le puede considerar como uno de los pilares de la cuestionada civilización occidental, en este esfuerzo colectivo por reconstruir/construir un rompecabezas de elementos sustentadores de nuevas formas de organizar la vida, se pueden recuperar incluso algunos elementos de la "vida buena" de Aristóteles.

El Buen Vivir, entonces, no es una originalidad ni una novelería de los procesos políticos de inicios del siglo XXI en los países andinos. Los pueblos y nacionalidades ancestrales del Abya-Yala no son los únicos portadores de estas propuestas. El Buen Vivir forma parte de una larga búsqueda de alternativas de vida fraguadas en el calor de las luchas de la Humanidad por la emancipación y la vida. 


\section{El desarrollo, un fantasma inalcanzable}

Pero antes de analizar estas propuestas indígenas, conviene señalar que desde mediados del siglo XX un fantasma recorre el mundo... ese fantasma es el desarrollo. Y a pesar de que la mayoría de personas, con seguridad, no cree en fantasmas, al menos en algún momento ha creído en "el desarrollo", se ha dejado influir por "el desarrollo" y es muy probable que lo siga haciendo en la actualidad.

Sin negar la vigencia del proceso buscado para satisfacer las necesidades de los seres humanos, existente desde hace mucho tiempo atrás, este fantasma del desarrollo se institucionalizó hace poco más de seis décadas. Se asume comúnmente como punto de partida el discurso del presidente de los Estados Unidos, Harry Truman, el 20 de enero de 1949. Este gobernante, en el "punto cuarto" de su intervención ante el Congreso, definió a la mayor parte del mundo como "áreas subdesarrolladas". Y anunció que todas las sociedades tendrían que recorrer la misma senda y aspirar a una sola meta: "el desarrollo".

Así, desde entonces se proyectó con fuerza esta suerte de mandato al resto del mundo. Esta metáfora: el desarrollo, tomada de la vida natural, se transformó en una meta a ser alcanzada por toda la Humanidad. Ha sido y es aún una suerte de estandarte que moviliza y uniformiza todo tipo de esfuerzos, y que justifica incluso gran cantidad de desatinos. Se convirtió, esto es fundamental, en un mandato que implicaba la difusión del modelo de sociedad norteamericana, heredera de muchos valores europeos.

De esta manera, después la Segunda Guerra Mundial, cuando arrancaba la Guerra Fría, con el surgimiento de la amenaza del terror nuclear, con el discurso sobre "el desarrollo" se consolidó una vieja estructura de dominación dicotómica: avanzadoatrasado, civilizado-primitivo, pobre-rico, a la que sumaron las visiones de centro-periferia, de desarrollado-subdesarrollado... Es preciso tener presente que este discurso del desarrollo apenas constituye una prolongación del mandato civilizatorio del progreso, como veremos más adelante.

A partir de dicha visualización, el mundo se ordenó para alcanzar el "desarrollo". Afloraron planes, bancos especializados para financiar el desarrollo, ayuda al desarrollo, cursos y formación para el desarrollo, comunicación para el desarrollo y un muy largo etcétera.

Alrededor del "desarrollo" giró, desde entonces, lo que conoció de manera simplona el enfrentamiento entre el capitalismo y el comunismo. Se inventó el Tercer Mundo y asumimos su existencia sin objeción. En este contexto de "guerra fría", los países de este muy mal llamado Tercer Mundo fueron instrumentalizados cual peones en el ajedrez de la geopolítica internacional. Desde la una y la otra vertiente, estableciendo las diversas especificidades y diferencias, todos los países asumieron el reto de alcanzar "el desarrollo". A lo largo y ancho del planeta, las comunidades y las sociedades fueron y continúan siendo reordenadas para adaptarse al "desarrollo". 
En nombre del "desarrollo" los países centrales o desarrollados, es decir nuestros referentes, promovieron diversos operativos de intervención e interferencia en los asuntos internos de los países periféricos o subdesarrollados. Así, registramos recurrentes intervenciones económicas a través del FMI y del Banco Mundial, e inclusive acciones militares para impulsar "el desarrollo" de los países atrasados protegiéndoles de la influencia de alguna de las potencias rivales. Mientras tanto, los países pobres, en un acto de generalizada subordinación y sumisión, aceptaron este estado de cosas siempre que se les considere países en desarrollo o en vías de desarrollo.

No hay que olvidar, que el proceso para alcanzar el desarrollo venía acompañado de una idea de homologación de la sociedad, no solamente porque el referente era una economía que generaba riqueza a partir de la acumulación del capital, sino porque todos los individuos debían tener similares necesidades y hacer todo lo posible por satisfacerlas.

De esta manera, los países considerados como atrasados, casi sin beneficio de inventario, aceptaron aplicar un conjunto de políticas, instrumentos e indicadores para salir del "subdesarrollo".

El entusiasmo no duró mucho. Cuando los problemas comenzaron a minar nuestra fe en "el desarrollo", buscamos alternativas de desarrollo. Le pusimos apellidos al desarrollo para diferenciarlo de lo que nos incomodaba, pero seguimos en la misma senda: desarrollo económico, desarrollo social, desarrollo local, desarrollo global, desarrollo rural, desarrollo sostenible o sustentable, ecodesarrollo, desarrollo a escala humana, desarrollo endógeno, desarrollo con equidad de género, codesarrollo... desarrollo al fin y al cabo. "El desarrollo", como toda creencia nunca fue cuestionado en su esencia, simplemente se le redefinió desde sus consecuencias y debilidades.

A lo largo de estas últimas décadas, casi todos los países del mundo no desarrollado han intentado alcanzar el desarrollo. ¿Cuántos lo han logrado? Muy pocos, eso si aceptamos que lo que consiguieron es realmente "el desarrollo".

Poco a poco, y esto es lo que más nos interesa en esta ocasión, se cayó en cuenta que el tema no es simplemente aceptar una u otra senda hacia el desarrollo. Los caminos hacia el desarrollo no son el problema mayor. La dificultad radica en el concepto. El desarrollo, en tanto propuesta global y unificadora desconoce de una manera violenta los sueños y luchas de los pueblos subdesarrollados, muchas veces por la acción directa de las naciones consideradas como desarrolladas (muchas de ellas colonizadoras del mundo empobrecido por efecto de esa colonización, cabría anotar).

Además, el desarrollo, en tanto reedición de los estilos de vida de los países centrales, resulta irrepetible a nivel global. Sabemos cada vez con más certeza que las crecientes prácticas consumistas y depredadoras están poniendo en riesgo el equilibrio ecológico global; un consumismo que perversamente margina cada vez más masas de seres humanos de las (supuestas) ventajas del ansiado desarrollo. A pesar de los indiscutibles avances tecnológicos, ni siquiera el hambre ha sido erradicada en el planeta; 
un flagelo que, cabe dejarlo sentado, no se da por la escasez de la oferta de alimentos, sino por la inequitativa e ineficiente distribución de los mismos.

El asunto es aún más complejo. No es solo una cuestión derivada de las inequidades e ineficiencias, que son inocultables. Se constata, cada vez con mayores certezas, que el mundo vive un "mal desarrollo" generalizado, incluyendo a aquellos países considerados como desarrollados. Bien anota José María Tortosa (2011: 54):

El funcionamiento del sistema mundial contemporáneo es "maldesarrollador" (...) La razón es fácil de entender: es un sistema basado en la eficiencia que trata de maximizar los resultados, reducir costes y conseguir la acumulación incesante de capital. (...) Si "todo vale", el problema no es de quién ha jugado qué cuándo, sino que el problema son las mismas reglas del juego. En otras palabras, el sistema mundial está "maldesarrollado" por su propia lógica y es a esa lógica a donde hay que dirigir la atención.

Ahora, cuando crisis múltiples y sincronizadas ahogan al planeta, nos encontramos con que este fantasma ha provocado y sigue provocando funestas consecuencias. El desarrollo (o el mismo progreso) puede incluso no tener un contenido evidentemente constructivo, pero justifica la utilización de todo tipo de medios, incluyendo los fracasos y hasta las crecientes devastaciones socioambientales.

En suma, hemos aceptado las reglas del "todo vale". ${ }^{2}$ Todo se tolera en nombre de la salida del subdesarrollo. Todo se santifica en nombre de una meta tan alta y prometedora como el progreso. Tenemos que al menos parecernos a los superiores y para lograrlo, cualquier sacrificio vale. No importa negar nuestras raíces históricas y culturales para progresar, para desarrollarnos, para modernizarnos emulando a los países adelantados, es decir modernos. Y lo que es lamentable, en la medida que asumimos modelos externos como la meta a alcanzar, negamos las posibilidades de una transformación propia.

Todo esto se desenvuelve en un proceso de mercantilización a ultranza. Hemos asumido como normal, en todo el mundo, que todo se compra, todo se vende. Tanto es así, que para que el mundo pobre salga de su pobreza, el mundo rico ha establecido que el pobre debe ahora pagar para imitarlos: comprar hasta su conocimiento, negando sus propios saberes y prácticas ancestrales.

Para conseguir el desarrollo, por ejemplo, se acepta la grave destrucción social y ecológica que provoca la megaminería o la explotación de hidrocarburos, a pesar de que estas actividades ahondan la modalidad de acumulación extractiva heredada desde la colonia.

${ }^{2}$ Se conoce como "todo vale" aquella modalidad de combate, donde los luchadores pueden usar cualquier arte marcial o deporte de contacto, ya que las reglas permiten cualquier técnica y forma de enfrentamiento. 
En este punto, ante el fracaso manifiesto de la carrera detrás del fantasma del desarrollo, emerge con fuerza la búsqueda de alternativas al desarrollo. Es decir de formas de organizar la vida fuera del desarrollo, superando el desarrollo, en suma rechazando aquellos núcleos conceptuales de la idea de desarrollo convencional entendido como progreso lineal. Lo que necesariamente implica superar el capitalismo y sus lógicas de devastación social y ambiental.

Sin embargo, aun cuando "la idea de desarrollo es ya una ruina en nuestro paisaje intelectual,...su sombra ...oscurece aún nuestra visión...” (de Souza Silva, 2010). En buen romance, sabemos que no podemos seguir detrás del fantasma del desarrollo. Su influencia nos pesará por largo rato y del desarrollo escaparemos arrastrando muchas de sus taras. Y por eso seguimos discutiendo sobre el desarrollo, que es, en realidad, como la luz de alguna lejana estrella ya desaparecida en el Universo.

\section{El progreso, antesala del desarrollo}

Si la idea de desarrollo está en crisis en nuestro paisaje intelectual, necesariamente debemos cuestionar el concepto de progreso, que emergió con fuerza hace más de 500 años en Europa. Los elementos sustanciales de la visión dominante impuesta por el desarrollo se nutren de los valores impuestos por el progreso civilizatorio de Europa. Un proceso en extremo expansionista e influyente, tanto como destructivo.

A partir de 1492, cuando España y poco después Portugal, invadieron nuestra Abya Yala (América) con una estrategia de dominación para la explotación, Europa impuso su imaginario para legitimar la superioridad del europeo, el "civilizado", y la inferioridad del otro, el "primitivo". En este punto emergieron la colonialidad del poder, la colonialidad del saber y la colonialidad del ser. Dichas colonialidades, vigentes hasta nuestros días, no son solo un recuerdo del pasado, explican la actual organización del mundo en su conjunto, en tanto punto fundamental en la agenda de la Modernidad, como anota con justeza Aníbal Quijano. ${ }^{3}$

Para cristalizar este proceso expansivo, Europa consolidó aquella visión que puso al ser humano figurativamente hablando por fuera de la Naturaleza. Se definió la Naturaleza sin considerar a la Humanidad como parte integral de la misma. Y con esto quedó expedita la vía para dominarla y manipularla.

Sir Francis Bacon (1561-1626), célebre filósofo renacentista, plasmó esta ansiedad en un mandato, al reclamar que "la ciencia torture a la Naturaleza, como lo hacía el

${ }^{3}$ Entre las múltiples obras de Quijano se recomienda: “¿Bien vivir?: entre el "desarrollo” y la descolonialidad del poder" (2011) Revista Ecuador Debate (84), Quito: CAAP; "Des/colonialidad del poder-El horizonte alternativo" (2009), en Acosta, Alberto y Esperanza Martínez (eds.). PlurinacionalidadDemocracia en la diversidad. Quito: Abya Yala. 
Santo Oficio de la Inquisición con sus reos, para conseguir develar el último de sus secretos..." ${ }^{4}$ Las consecuencias de este mandato las vivimos en la actualidad.

Pero no fue solo Bacon. René Descartes (1596-1650), uno de los pilares del racionalismo europeo, consideraba que el universo es una gran máquina sometida a leyes. Todo quedaba reducido a materia (extensión) y movimiento. Con esta metáfora, él hacía referencias a Dios como el gran relojero del mundo, encargado no solo de "construir" el universo, sino de mantenerlo en funcionamiento. $\mathrm{Y}$ al analizar el método de la incipiente ciencia moderna, decía que el ser humano debe convertirse en dueño y poseedor de la Naturaleza. De esta fuente cartesiana se han nutrido otros filósofos notables que han influido en el desarrollo de las ciencias, tecnología y técnicas. Por cierto que esta visión de dominación tiene también profundas raíces judeocristianas. ${ }^{5}$

En el terreno práctico, Cristóbal Colón, con su histórico viaje en 1492, sentó las bases de la dominación colonial, con consecuencias indudablemente presentes hasta nuestros días. Colón buscaba recursos naturales, especialmente especerías, sedas, piedras preciosas y sobre todo oro. ${ }^{6} \mathrm{Su}$ viaje, en consecuencia, abrió necesariamente la puerta a la conquista y la colonización. Con ellas, en nombre del poder imperial y de la fe, empezó una explotación inmisericorde de recursos naturales, con el consiguiente genocidio de muchas poblaciones indígenas.

La desaparición de pueblos indígenas enteros, es decir mano de obra barata y sometida, que moría masivamente por efecto de la conquista y la colonia, se cubrió con la incorporación de esclavos provenientes de África; esclavos que luego constituirían un importante aporte para el proceso de industrialización al ser mano de obra en extremo de poco costo. ${ }^{7} \mathrm{Y}$ desde entonces, para sentar las bases del mercado global, se fraguó un esquema extractivo de exportación de Naturaleza desde las colonias en función de las demandas de acumulación del capital de los países imperiales, los actuales centros del entonces naciente sistema capitalista.

${ }^{4}$ Sobre esta afirmación se puede consultar en Max Neef, Manfred Conferencia dictada en noviembre del 2005, en la Universidad EAFIT, Medellín Colombia.

$<$ http://www.max-neef.cl/download/Max_Neef_El_poder_de_la_globalizacion.pdf $>$, publicada en la Revista Futuros No. 14, 2006 Vol. IV <http://www.revistafuturos.info >

${ }^{5}$ En el Génesis se lee: "Hagamos al ser humano a nuestra imagen y semejanza. Que tenga dominio sobre los peces del mar, y sobre las aves del cielo; sobre los animales domésticos, sobre los animales salvajes, y sobre todos los reptiles que se arrastran por el suelo."

${ }^{6}$ Según Colón, quien llegó a mencionar 175 veces en su diario de viaje a este metal precioso, "el oro es excelentísimo; del oro se hace tesoro, y con él, quien lo tiene, hace cuanto quiere en el mundo, y llega incluso a llevar las almas al paraiso"

${ }^{7}$ Esto lo reconocería con claridad Carlos Marx: "Sin esclavitud no habría algodón; sin algodón no habria industria moderna. La esclavitud ha dado su valor a las colonias, las colonias han creado el comercio universal, el comercio universal es la condición necesaria de la gran industria. Por tanto, la esclavitud es una categoría económica de la más alta importancia." 
Estos son algunos de los elementos fundacionales de aquella idea de progreso y civilización dominantes aún. Ideas que han amamantado al desarrollo, convirtiéndolo en una herramienta neocolonial. Así, América, al ser incorporada como fuente de recursos naturales, y África, en especial como fuente de energía barata, apuntalaron el nacimiento del capitalismo en tanto civilización de alcance global.

Pasados los siglos, en la actualidad todo indica que el tan ansiado progreso, sintetizado comúnmente en el crecimiento material sin fin, podría culminar en un suicidio colectivo. Basta ver los efectos del mayor recalentamiento de la atmósfera, de la pérdida de fuentes de agua dulce, de la erosión de la biodiversidad agrícola y silvestre, de la degradación de suelos o de la acelerada desaparición de espacios de vida de las comunidades locales...

Bien sabemos ahora, que la acumulación material mecanicista e interminable de bienes, apoltronada en el aprovechamiento indiscriminado y creciente de la Naturaleza, no tiene futuro. Los límites de estilos de vida sustentados en esta visión ideológica del progreso clásico son cada vez más notables y preocupantes. Los recursos naturales no pueden ser más asumidos únicamente como una condición para el crecimiento económico, como tampoco pueden ser un simple objeto de las políticas de desarrollo.

La Humanidad, no solo América Latina, se encuentra en una encrucijada. La promesa hecha hace más de cinco siglos, en nombre del "progreso", y "reciclada" hace más de seis décadas, en nombre del "desarrollo", no se ha cumplido. Y no se cumplirá, porque en su esencia aflora la lógica devastadora del capitalismo.

\section{EI desarrollo, sus alternativas y sus limitaciones}

En especial desde la década de los sesentas y los setentas comenzaron a aparecer distintas visiones críticas, así como reclamos en el terreno económico, social y más tarde ambiental. América Latina jugó un papel importante en generar revisiones contestatarias al desarrollo convencional, como fueron el estructuralismo o los diferentes énfasis en la teoría de la dependencia, hasta llegar a otras posiciones más recientes.

Estas posturas heterodoxas y críticas encierran una importancia considerable, pero también adolecen de algunas limitaciones. Por un lado, sus planteamientos no lograron cuestionar seriamente los núcleos conceptuales de la idea de desarrollo convencional entendido como progreso lineal, y en particular expresado en términos del crecimiento económico. Por otro lado, cada uno de esos cuestionamientos generó una ola de revisiones que no pudieron sumarse y articularse entre sí. En algunos casos generaron un pico en las críticas e incluso en las propuestas, pero poco después estos esfuerzos languidecieron y las ideas convencionales retomaron el protagonismo.

La confianza en el desarrollo, en tanto proceso planificado para superar el atraso, se resquebrajó en las décadas de los 80 y los 90. Esto contribuyó a abrir la puerta a las 
reformas de mercado de inspiración neoliberales, en las que, en estricto sentido, la búsqueda planificada y organizada del desarrollo de épocas anteriores debía ceder paso a las pretendidas todopoderosas fuerzas del mercado. Esto, sin embargo, no implicó que se habría superado la ideología del progreso de raigambre colonial, todo lo contrario. El neoliberalismo reproduce una mirada de las perspectivas hegemónicas del Norte global.

Pero, nuevamente, a partir de fines de la década de 1990, los cuestionamientos afloraron con fuerza, en particular como reacción frente al creciente reduccionismo de mercado. Además, las posturas neoliberales, que consideran que el desarrollo no es un proceso a construir o planificar, sino que resulta de dejar actuar libremente al mercado, naufragaron. Su estruendoso fracaso económico en muchos países de América Latina se reflejó en crecientes conflictos sociales y en un aumento de los problemas ambientales, lo que exacerbó las desigualdades y las frustraciones.

Así las cosas, en los albores del siglo XXI, el estilo de desarrollo neoliberal comenzó a agotarse. Esto contribuyó a varios recambios políticos en algunos países de América Latina, cuya expresión más nítida ha sido la llegada al poder del progresismo sudamericano ${ }^{8}$. Sin duda los procesos en juego son diversos, y los tonos de cada uno de los nuevos gobiernos también es distinto, pero en todos ellos se comparte un rechazo al reduccionismo neoliberal, pero que arrastra en muchos casos sus valores. Se busca el reencuentro con los sectores populares, pero a través de un marcado asistencialismo, la defensa del protagonismo del Estado, pero con las mismas lógicas dependientes, y acciones más enérgicas para reducir la pobreza, pero empujando a amplios sectores al consumismo y sin una real política redistributiva. Y ese Estado "recuperado", con un creciente despliegue de acciones represivas y autoritarias, es el que procesa cambios anhelados por los neoliberales, como lo es la expansión de la frontera extractivista: minera, petrolera o agrícola.

El núcleo básico desarrollista persiste aún en el mal llamado "socialismo del siglo XXI". Este nuevo orden político moderniza el capitalismo y construye nuevos esquemas corporativistas. Hoy, por ejemplo, se realizan enormes obras de infraestructura, con los mismos valores neoliberales: la eficiencia, la competitividad y la excelencia, para forzar el extractivismo; modalidad de acumulación que, más allá de algunas diferencias relativamente menores y por cierto de algunos estridentes discursos soberanistas, mantiene la misma matriz colonial de hace más de quinientos años. ${ }^{9}$ Este proceso que se podría llamar extractivismo del siglo XXI presenta, sin embargo, algunas diferencias con el extractivismo de los gobiernos neoliberales.

${ }^{8}$ Es necesario diferenciar entre la izquierda y el progresismo. Este último, sin ser conservador, no puede ser considerado como de izquierda, como acertadamente plantea Eduardo Gudynas (2014).

${ }^{9}$ Ver Acosta (2011). 


\section{El Buen Vivir, propuesta de cambio civilizatorio desde la periferia del mundo}

En este punto reconozcamos que, mientras buena parte de las posturas sobre el desarrollo e incluso muchas de las corrientes críticas se desenvuelven dentro de los saberes occidentales propios de la Modernidad, las propuestas latinoamericanas de origen indígena escapan a esos límites.

Así las críticas y las construcciones alternativas ganaron un nuevo protagonismo con los aportes de los pueblos indígenas y también de otros sectores populares. Sus propuestas incluyen diversos cuestionamientos al desarrollo, tanto en los planos prácticos como en los conceptuales. No hay como olvidar que, en paralelo, empezaron a consolidarse, además, los aportes y las alternativas ecologistas.

Sobre todo en estos últimos años, en el marco de los debates posdesarrollistas ${ }^{10}$, se multiplicaron los esfuerzos por una reconstrucción e incluso por la superación de la base conceptual, las prácticas, las instituciones y los discursos del desarrollo. En este estado de cosas, por un lado se ubican las críticas al desarrollo, y por otro, la búsqueda de alternativas al desarrollo. Desde ese contexto aflora el Buen Vivir o Sumak Kawsay.

Las críticas al desarrollo han calado mucho más profundo que en épocas anteriores. Es cada vez más aceptado que los problemas no radican en las mediaciones o instrumentalizaciones de diferentes opciones de desarrollo. Se entiende también que no se trata de hacer mejor o simplemente bien lo que se había propuesto anteriormente. Los cuestionamientos comprenden que es necesario ir a las bases conceptuales, incluso ideológicas o culturales, en las que se sustenta el desarrollismo convencional.

Desde la otra orilla, no se trata solo de criticar el desarrollo. Es indispensable construir alternativas al desarrollo, no simples alternativas de desarrollo. El Buen Vivir $o$ Sumak Kawsay, planteado desde el mundo andino y amazónico, pero que rebasa estos espacios geográficos, es una de esas alternativas.

Lo interesante es que el Buen Vivir, en tanto sumatoria de prácticas vivenciales de resistencia al colonialismo y sus secuelas, es todavía un modo de vida en muchas comunidades indígenas, que no han sido totalmente absorbidas por la Modernidad capitalista o que han resuelto mantenerse al margen de ella.

Dejemos sentado desde el inicio que el Buen Vivir o Sumak Kawsay no sintetiza ninguna propuesta totalmente elaborada, menos aún pretende tener una posición indiscutible. El Buen Vivir no quiere asumir el papel de un mandato global, como sucedió con "el desarrollo" a mediados del siglo XX. El Buen Vivir es un camino que debe

${ }^{10}$ La lista de autores que abordan la crítica al desarrollo y la construcción de alternativas al desarrollo es cada vez más grande. Recomiendo la lectura de los textos de Jürgen Schuldt y Enrique Leff, así como los aportes de Koldo Unceta, que ubican con claridad estos temas (varios de sus trabajos se encuentran mencionados en la bibliografía). 
ser imaginado para ser construido. El Buen Vivir será, entonces, una construcción que pasa por desarmar la meta universal para todas las sociedades: el progreso en su deriva productivista y el desarrollo en tanto a un dirección única, sobre todo en su visión mecanicista y lineal de crecimiento económico, así como sus múltiples sinónimos. Pero no solo los desarma, el Buen Vivir propone una visión diferente, mucho más rica en contenidos y, por cierto, más compleja.

El Buen Vivir, en realidad, se presenta como una oportunidad para construir colectivamente nuevas formas de vida. No sintetiza una visión retro, como simplonamente se ha llegado a afirmar. No se trata simplemente de un recetario plasmado en unos cuantos artículos constitucionales; recordemos que en la Constitución de Ecuador (2008) y Bolivia (2009) fue incorporado este concepto. El Buen Vivir, ya lo dijimos, no es una originalidad ni una novelería de los procesos políticos de inicios del siglo XXI en los países andinos. El Buen Vivir forma parte de una larga búsqueda de alternativas de vida fraguadas en el calor de las luchas populares, particularmente de los pueblos y nacionalidades originarios. Esto no significa que solo hay propuestas en el mundo andino y amazónico. En contextos diversos, a lo largo y ancho del planeta, existen acciones y visiones que pueden entrar en sintonía con el Buen Vivir.

Lo destacable y profundo de estas propuestas alternativas, de todas formas, es que surgen desde grupos tradicionalmente marginados. Son propuestas que invitan a romper de raíz con varios conceptos asumidos como indiscutibles.

En suma, estas visiones posdesarrollistas superaron los aportes de las corrientes heterodoxas críticas, que surgieron sobre todo en América Latina en los años sesenta y setenta, antes mencionadas, que proponía "desarrollos alternativos". En la actualidad es cada vez más necesario generar "alternativas al desarrollo". De eso se trata el Buen Vivir.

Bajo algunos saberes indígenas no existe una idea análoga a la de desarrollo, lo que lleva a que en muchos casos se rechace esa idea. No existe la concepción de un proceso lineal de la vida que establezca un estado anterior y posterior, a saber, de subdesarrollo y desarrollo; dicotomía por la que deben transitar las personas para la consecución del bienestar, como ocurre en el mundo occidental. Tampoco existen conceptos de riqueza y pobreza determinados por la acumulación y la carencia de bienes materiales.

El Buen Vivir asoma como una categoría en permanente construcción y reproducción. En tanto planteamiento holístico, es preciso comprender la diversidad de elementos a los que están condicionadas las acciones humanas que propician el Buen Vivir, como son el conocimiento, los códigos de conducta ética y espiritual en la relación con el entorno, los valores humanos, la visión de futuro, entre otros. El Buen Vivir o Sumak Kawsay, en definitiva, constituye una categoría central de la filosofía de la vida de las sociedades indígenas (Viteri Gualinga, 2000).

Desde esa perspectiva, el desarrollo convencional es visto como una imposición cultural heredera del saber occidental, por lo tanto colonial. Entonces, las reacciones contra la colonialidad, imperante todavía en la actualidad, implican un distanciamiento 
del desarrollismo. La tarea es descolonizadora; así como también despatriarcalizadora y superadora de toda forma de racismo, por supuesto. Sobre todo se requiere un proceso de descolonización intelectual para descolonizar la política, la sociedad, la economía.

El Buen Vivir, en definitiva, plantea una cosmovisión diferente a la occidental al surgir de raíces comunitarias no capitalistas. Rompe por igual con las lógicas antropocéntricas del capitalismo en tanto civilización dominante y también de los diversos socialismos realmente existentes hasta ahora, que deberán repensarse desde posturas sociobiocéntricas. Se ha demostrado la necesidad de superar el capitalismo en tanto "civilización de la desigualdad" (Joseph Schumpeter). Una civilización en esencia depredadora y explotadora. Un sistema que "vive de sofocar a la vida y al mundo de la vida" (Bolívar Echeverría, 2010). El Buen Vivir, en consecuencia, propone un cambio civilizatorio.

Los saberes comunitarios, muchos de ellos ancestrales — esto es lo que cuenta-, constituyen la base para imaginar y pensar un mundo diferente como un camino para cambiar éste. De todas maneras, siempre será un problema comprobar lo que es y lo que representa un saber ancestral cuando probablemente lo que se presenta como tal no es realmente ancestral, ni hay modo de corroborarlo. Las culturas son tan heterogéneas en su interior que puede resultar injusto hablar de nuestra cultura como prueba de que lo que uno dice es correcto. Además, la historia de la Humanidad es la historia de los intercambios culturales y, como bien vio José María Arguedas, eso también se aplica a las comunidades originarias americanas. Es imperioso, de todos modos, recuperar las prácticas y vivencias de las comunidades indígenas, asumiéndolas tal como son, sin llegar a idealizarlas.

En realidad para hablar del Buen Vivir o Sumak Kawsay hay que recurrir a las experiencias, visiones y propuestas de aquellos pueblos - dentro y fuera del mundo andino y amazónico - empeñados en vivir en armonía entre sí y con la Naturaleza, poseedores de una historia larga y profunda, todavía bastante desconocida e incluso marginada. Tengamos presente que los pueblos indígenas no son premodernos, ni atrasados. Sus valores, experiencias y prácticas sintetizan una civilización viva, que ha enfrentado los problemas de la Modernidad colonial. Han sido capaces de apropiarse de sus recursos para resistir a su propia manera un colonialismo que dura ya más de quinientos años, llegando incluso a imaginar un futuro distinto al actual, que bien puede nutrir los debates globales, como veremos más adelante.

Dicha armonía, de ninguna manera, puede llevar a creer en la posibilidad de un paraíso carente de conflictos. En las sociedades humanas habrá siempre contradicciones y tensiones, inclusive en su relacionamiento con el entorno natural. Una situación que se ha exacerbado peligrosamente con la civilización capitalista.

No hay forma de escribir sobre esta cuestión a partir de un reducto académico aislado de los procesos sociales, es decir sin nutrirse de las experiencias y luchas del mundo indígena y de otras que empiezan a surgir incluso en las metrópolis de Latinoamérica; un mundo que no solo se encuentra en las regiones rurales de los Andes y la Amazonia. 
Entonces, estas líneas, en las que la responsabilidad las asume íntegramente el autor, no constituyen un producto de autoría individual. Y menos aún pueden ser entendidas como verdades reveladas. Con este aporte se pretende seguir echando leña en el fuego del debate. Y también se quiere dar algunas luces para la acción.

En este punto cabe descubrir el riesgo que representan aquellas visiones que pretenden diferenciar el Buen Vivir del Sumak Kawsay, a los que asume como dos paradigmas diferentes (Oviedo Freire, 2014). Es innegable que hay una apropiación, secuestro y domesticación del término por los gobiernos de Ecuador y de Bolivia. Nadie duda que el Buen Vivir gubernamental está desencontrado con el Buen Vivir de origen indígena. Eso explica esa posición separatista entre Buen Vivir y Sumak Kawsay, como rechazo a esas manipulaciones gubernamentales, pero no la justifica. Eduardo Gudynas (2014), en un artículo en el mismo libro en que aparece la posición de Oviedo Freire, anota que con esta separación "se pierde la pluralidad original y el concurso de las posturas críticas a la Modernidad no-indígena". Sostener que el Buen Vivir, por definición es desarrollista, y que el Sumak Kawsay, en consecuencia, es indígena, es una simplificación que no contribuye al debate. Además, esta distinción y separación recluiría las propuestas indígenas en un mundo estrecho y se minimizarían sus enormes potencialidades derivadas para librar una batalla conceptual y política orientada a superar la Modernidad.

Lo destacable y profundo de estas propuestas es, entonces, que nos invitan a romper de raíz con varios conceptos asumidos como indiscutibles, empezando por el concepto tradicional de progreso y desarrollo.

\section{Hacia un reencuentro con la Naturaleza}

La propuesta del desarrollo, surgida desde la lógica del progreso civilizatorio de occidente, forzó aún más la antigua dicotomía salvaje-civilizado, que se introdujo de manera violenta hace más de cinco siglos en América con la conquista europea. Y la acumulación material — mecanicista e interminable de bienes - asumida como progreso, agudizó la destrucción de la Naturaleza (Gudynas, 2009).

Desde una perspectiva global, los límites de los estilos de vida sustentados en la visión ideológica del progreso antropocéntrico son cada vez más notables y preocupantes. Si queremos que la capacidad de absorción y resilencia ${ }^{11}$ de la Tierra no colapse, debemos dejar de ver a los recursos naturales como una condición para el crecimiento. Y por cierto debemos aceptar que lo humano se realiza en comunidad, con y en función de otros seres humanos, como parte integrante de la Naturaleza, sin pretender dominarla.

${ }^{11}$ La resiliencia, en el campo de la ecología, es la capacidad que tiene la Naturaleza de volver al estado original, especialmente después de alguna situación crítica e inusual. 
Desde los albores de la Humanidad el miedo a los impredecibles elementos de la Naturaleza estuvo presente en la vida de los seres humanos. Poco a poco la ancestral y difícil lucha por sobrevivir se fue transformando en un desesperado esfuerzo por dominar la Naturaleza. Paulatinamente el ser humano, con sus formas de organización social antropocéntricas, se puso figurativamente hablando por fuera de la Naturaleza. Se llegó a definir la Naturaleza sin considerar a la Humanidad como parte integral de la misma. Y con esto quedó expedita la vía para dominarla y manipularla, sobre todo en la civilización capitalista.

Frente a esta añeja visión de dominación y explotación, sostenida en el divorcio profundo de la economía y la Naturaleza, causante de crecientes problemas globales, han surgido varias voces de alerta. El punto es claro, la Naturaleza no es infinita, tiene límites y estos límites están siendo superados.

La crisis provocada por la superación de los límites de la Naturaleza conlleva necesariamente a cuestionar la institucionalidad y la organización sociopolítica. No hacerlo amplificaría aún más las tendencias excluyentes y autoritarias, así como las desigualdades e inequidades tan propias del sistema capitalista.

La tarea parece simple, pero es en extremo compleja. En lugar de mantener el divorcio entre la Naturaleza y el ser humano, hay que propiciar su reencuentro. Para lograr esta transformación civilizatoria, una de las tareas iniciales radica en la desmercantilización de la Naturaleza. Los objetivos económicos deben estar subordinados a las leyes de funcionamiento de los sistemas naturales, sin perder de vista el respeto a la dignidad humana procurando asegurar la calidad en la vida de las personas. Y esto se logra con verdaderos procesos de redistribución del ingreso y de la riqueza.

Uno de los pasos concretos, luego de las reflexiones anteriores, fue el dado en la Asamblea Constituyente de Montecristi en Ecuador, al otorgarle derechos a la Naturaleza. Esto ubica con claridad por dónde debería marchar la construcción de una nueva forma de organización de la sociedad, si realmente pretende ser una opción de vida, en tanto respeta y convive dentro de la Naturaleza.

En dicha Constitución, aprobada el año 2008, al sumar a la Naturaleza como sujeto de derechos, y al otorgarle el derecho a ser restaurada cuando ha sido destruida, se estableció un hito en la historia de la Humanidad. La restauración difiere de la reparación que es un recurso para los seres humanos, cuyas condiciones de vida puedan verse afectadas por algún deterioro ambiental provocado por otros seres humanos. Por igual trascendente fue la incorporación del término Pacha Mama, como sinónimo de Naturaleza, en tanto reconocimiento de plurinacionalidad e interculturalidad. Y por cierto fue trascendente la aceptación del agua como un Derechos Humano fundamental, no simplemente el acceso al agua; con lo cual se prohibió toda forma de privatización del agua.

A lo largo de la historia, cada ampliación de los derechos fue anteriormente impensable. La emancipación de los esclavos o la extensión de los derechos a los pueblos afro, a las mujeres y a los niños y niñas fueron una vez rechazadas por ser consideradas 
como un absurdo. Se ha requerido que se reconozca el derecho de tener derechos y esto se ha conseguido siempre con una intensa lucha política para cambiar aquellas leyes que negaban esos derechos.

La liberación de la Naturaleza de esta condición de sujeto sin derechos o de simple objeto de propiedad, exigió y exige, entonces, un esfuerzo político que le reconozca como sujeto de derechos. Este aspecto es fundamental si aceptamos que todos los seres vivos tiene el mismo valor ontológico, lo que no implica que todos sean idénticos. Lo central de los Derechos de la Naturaleza es rescatar el derecho a la existencia de los propios seres humanos.

Por cierto que en este punto habría que relievar todos los aportes y las luchas desde el mundo indígena, en donde la Pacha Mama es parte consustancial de sus vidas. Pero igualmente, y esto también es importante, hay razones científicas que consideran a la Tierra como un súper organismo vivo. Este súper organismo extremadamente complejo, requiere de cuidados y debe ser fortalecido, es sujeto de dignidad y portador de derechos, porque todo lo que vive tiene un valor intrínseco, tenga o no uso humano. Incluso hay razones cosmológicas que asumen a la tierra y a la vida como momentos del vasto proceso de evolución del Universo. La vida humana es, entonces, un momento de la vida en términos amplios. Y para que esa vida pueda existir y reproducirse necesita de todas las precondiciones que le permitan subsistir. En todas estas visiones aflora como eje fundamental el principio indígena de la relacionalidad: todo tiene que ver con todo, en todos los puntos y en todas las circunstancias.

Entonces, lo que urge es caminar hacia la Declaración Universal de los Derechos de la Naturaleza, como punto de partida para empezar a reconstruir relaciones armoniosas de los seres humanos con su Madre Tierra.

\section{Los elementos de una economía solidaria y sustentable}

Esta demanda civilizatoria exige otra economía. Una economía sustentada en otros principios que los capitalistas. Se requieren principios fundacionales como los de solidaridad y sustentabilidad, a más de reciprocidad, complementariedad, responsabilidad, integralidad, relacionalidad, suficiencia (y de alguna manera también eficiencia), diversidad cultural e identidad, equidades, y por cierto siempre más democracia, nunca menos.

A partir de la aceptación de que una economía se sustente en la solidaridad y en la sustentabilidad, para mencionar apenas dos de los principios señalados en el párrafo anterior, se busca la construcción de otro tipo de relaciones de producción, de intercambio, de consumo, de cooperación y también de acumulación y de distribución del ingreso y la riqueza.

En el ámbito económico se requiere incorporar criterios de suficiencia antes que sostener la lógica de la eficiencia entendida como la acumulación material cada vez más 
acelerada, frente a la cual claudica incluso la democracia. De allí se desprende una indispensable crítica al fetiche del crecimiento económico, que es apenas un medio, no un fin.

Esto plantea también, como meta utópica, la construcción de relaciones armoniosas de la colectividad y no solo de individualidades entre sí; y, de estas con la Naturaleza. La actual meta de sociedades afincadas en la competitividad, lo sabemos muy bien, nos mueven hacia una cacotopía, es decir hacia una utopía negativa.

Pero no solo que están los límites ambientales. Hay otro punto crucial: el crecimiento económico, provocado por la voracidad del capital, que acumula produciendo y especulando, se da sobre bases de creciente inequidad estructural. Basta ver algunas cifras de la inequitativa distribución de la riqueza a nivel mundial: Las 85 personas más ricas del mundo tienen tanto como la mitad más pobre de la población mundial: 1700 millones de habitantes, según un reporte de la Oxfam (2014) ${ }^{12}$. Según dicho reporte, el $1 \%$ de la población más rica acapara casi la mitad de la riqueza mundial. Revisar las cifras de la inequidad en Alemania, el país de "los inventores" de la tan promocionada economía social de mercado, resulta por igual aleccionador: en el año 2008 , el $10 \%$ más rico de la población alemana poseía el 53\% de los activos, mientras que la mitad de la población es propietaria de un $1 \%$ de los activos (Revista Der Spiegel $\left.\mathrm{n}^{\circ} 19,2014\right)$.

El objetivo final es construir un sistema económico solidario, sustentado sobre bases comunitarias y orientadas por la reciprocidad, y subordinado a los límites que impone la Naturaleza. Es decir debe asegurar desde el inicio y en todo momento procesos económicos respetuosos de los ciclos ecológicos, que puedan mantenerse en el tiempo, sin ayuda externa y sin que se produzca una escasez crítica de los recursos existentes.

Para lograr este objetivo múltiple será preciso transitar por sendas que permitan ir dejando atrás paulatinamente las lógicas de devastación social y ambiental dominantes en la actualidad. El mayor desafío de las transiciones ${ }^{13}$ se encuentra en superar aquellos patrones culturales asumidos por la mayoría de la población que apuntan hacia una permanente y mayor acumulación de bienes materiales. Una situación que, como bien sabemos, no asegura necesariamente un creciente bienestar de todos los individuos y las colectividades. Tenemos a mano la sólida demostración de que un incremento del ingreso per cápita no ha mejorado los índices de felicidad en varias décadas en los Estados Unidos y en muchos otros países considerados como desarrollados.

12 Gobernar para las élites-Secuestro democrático y desigualdad económica,

$<$ http://www.oxfam.org/sites/www.oxfam.org/files/bp-working-for-few-political-capture-economic-inequality-200114-es.pdf>

${ }^{13}$ En la actualidad hay muchos proyectos empeñados en impulsar estas transiciones. Destaco la tarea emprendida por el Grupo Permanente de Trabajo sobre Alternativas al Desarrollo de la Fundación Rosa Luxemburgo, que ya ha publicado dos libros Más allá del desarrollo (2011) y Alternativas al capitalismo y colonialismo del siglo XXI (2013). Otro aporte digno de ser mencionado es el libro Transiciones, postextractivismo y alternativas al extractivismo en el Perú de Alejandra Alayza y Eduardo Gudynas (eds.) (2011). 
De todas maneras, la combinación de los diversos factores de producción en función de las demandas del capital, para asegurar un mayor crecimiento económico y quizás también bienestar, sin preocuparse por la solidaridad y la sustentabilidad, en función de la acumulación del capital, ha sido y es todavía la principal preocupación de los economistas ortodoxos. Y si esto es así, esa aceptación ha permeado en amplios segmentos de la población que la asumen como una realidad indiscutible.

Con el fin de enfrentar esta economía ortodoxa, en cualquiera de sus versiones, hay que dar paso a una gran transformación (en palabras de Carlos Marx diríamos revolución). No solo hay que consumir mejor y en algunos casos menos, sino que debemos obtener mejores resultados con menos, en términos de mejorar la calidad de vida.

En definitiva, hay que construir otra lógica económica, que no radique en la ampliación permanente del consumo en función de la acumulación de capital. En consecuencia, esta nueva propuesta económica, que deberá enfrentar poderosos intereses de todo tipo, tiene que consolidarse particularmente superando el consumismo e inclusive el productivismo sobre bases de creciente autodependencia comunitaria en todos los ámbitos. No se trata de minimizar la importancia que tiene el Estado, pero sí de ubicarlo en su verdadera dimensión, es decir asumiendo sus limitaciones y repensándolo desde lo comunitario. ${ }^{14}$

Una nueva economía implica superar el fetiche del mercado, frente al que muchas personas bajan la cabeza: el mercado habla, el mercado reacciona, el mercado protesta, el mercado siente... Lo grave de subordinar el Estado al mercado, conduce a subordinar la sociedad a las relaciones mercantiles y al individualismo ególatra.

Si bien el mercado total no es la solución, tampoco lo es el Estado por sí solo. Tengamos presente, como un aspecto medular, que no todos los actores de la economía actúan movidos por el lucro. Y que tampoco la burocracia estatal puede suplantar las expresiones de las comunidades, en tanto ella no garantiza la participación popular en la toma de decisiones, ni el control democrático.

Eso nos lleva a comprender que en una economía solidaria, como parte de una sociedad plenamente democrática, no puede haber formas de propiedad capitalista, y tampoco la empresa pública o estatal puede totalizar la economía, al considerársela como la forma de propiedad principal y dominante. Hay otras formas de propiedad y organización en una economía solidaria: cooperativas de ahorro y crédito, de producción, de consumo, de vivienda y de servicios, así como mutuales de diverso tipo, asociaciones de productores y comercializadores, organizaciones comunitarias, unidades económicas populares o empresas autogestionarias, por ejemplo. Y en este universo habrá que incorporar a una gran multiplicidad de organizaciones de la sociedad civil, que pueden acompañar e incluso ser la base de una transformación que no se improvisa.

${ }^{14}$ En el mundo andino-amazónico se plantea la construcción de un Estado plurinacional e intercultural, que tendrá que ser ante todo un Estado comunitario. 
Esta economía solidaria y sustentable, entonces, parte de una marcada heterogeneidad de formas de propiedad y de producción. Desde donde, en un proceso programado de transiciones múltiples y que será de largo aliento, se deberán ir construyendo otras relaciones de producción y de control de la economía. El Estado tendrá un importante papel y por cierto también los mercados. La organización económica podría ser repensada, al menos inicialmente, desde la visión de economías socialistas de mercado, que de ninguna manera podrán seguir por la senda de la mercantilización generalizada tan propia del capitalismo.

Y el objetivo de esta nueva economía, ya desde la fase de transición, será impulsar la satisfacción de las necesidades actuales sin comprometer las posibilidades de las generaciones futuras en condiciones que aseguren relaciones cada vez más armoniosas de los seres humanos consigo mismo, de los seres humanos con sus congéneres y de los seres humanos con la Naturaleza. Este es uno de los puntos medulares del Buen Vivir o Sumak Kawsay.

Ya no se trata solamente de defender la fuerza de trabajo y de recuperar el tiempo de trabajo excedente para los trabajadores, es decir de oponerse a la explotación de la fuerza de trabajo. Eso es muy importante. Vital. Pero hay algo más. En juego está la defensa de la vida misma. Esto nos conmina a superar esquemas organizativos de privilegios antropocéntricos, causantes de la mayores desigualdades y, además, de la destrucción del planeta por la vía de la depredación y la degradación ambientales; situación exacerbada en el capitalismo. Así, los objetivos económicos, subordinados a las leyes de funcionamiento de los sistemas naturales, deben conciliarse con el respeto a la dignidad humana y la mejoría de la calidad de vida de las personas, las familias y las comunidades. De ninguna forma se puede sacrificar la Naturaleza y su diversidad. Hay que entender en la práctica que el ser humano forma parte de la Naturaleza y que no puede dominarla, mercantilizarla, privatizarla, destruirla.

El punto se centra en la aceptación de que la Naturaleza tiene límites que las economías no deben sobrepasar. El cambio climático, resultado del sobreconsumo energético, es una evidencia incontrastable. El pensamiento funcional se limita a hacer de "los bienes" y "servicios ambientales" simples elementos transables, a través de la dotación de derechos de propiedad sobre estas funciones. Una situación que se produce debido a la generalización de un comportamiento egoísta y cortoplacista, incapaz de reconocer que un recurso tiene un límite o umbral antes de colapsar.

Está claro, entonces, que la organización misma de la economía debe cambiar de manera profunda. Este es quizás uno de los mayores retos. El crecimiento económico, transformado en un fetiche al cual rinden pleitesía los poderes del mundo y amplios segmentos de la población, debe ser desenmascarado y desarmado. Igualmente se precisa desmontar la lógica extractiva que hunde nuestras economías en la dependencia. Algo fácil de decir, pero difícil de hacer al margen del consenso y participación popular. 
El camino de salida de una economía extractiva, por ejemplo, que tendrá que arrastrar por un tiempo algunas actividades de este tipo, debe considerar un punto clave: el decrecimiento planificado del extractivismo. La opción potencia actividades sustentables, que podrían darse en el ámbito de las manufactureras, la agricultura, el turismo, sobre todo el conocimiento... En definitiva, no se debe deteriorar más la Naturaleza. El éxito de este tipo de estrategias para procesar una transición social, económica, cultural, ecológica, dependerá de su coherencia y, sobre todo, del grado de respaldo social que tenga.

Al revisar la literatura disponible se observa que no existe un consenso específico de las diferentes conceptualizaciones de las prácticas económicas y sociales de las comunidades indígenas. Estas se hacen presentes en diferentes formas. Difieren desde el cotidiano vivir y desde los distintos territorios. Lo que interesa es que en sus raíces conllevan la idea principal y muy arraigada sobre la reciprocidad entre seres humanos que forman parte integral de la Pacha Mama.

Sin llegar a posiciones simplistas propias de comparaciones superficiales, aquí pueden incorporarse muchas otras visiones no solo provenientes de los pueblos y nacionalidades indígenas, sino de otras latitudes, como la propuesta de "sobriedad feliz" de Pierre Rabhi (2013) en Francia ${ }^{15}$. También son oportunas las reflexiones de la Academia para Economía Solidaria en Alemania cuando hablan de la suficiencia, por ejemplo. ${ }^{16}$

En consecuencia, esta nueva economía deberá ser repensada desde una visión holística y sistémica, plasmada en los Derechos Humanos y en los Derechos de la Naturaleza.

Las transiciones, en tanto a rutas hacia una nueva civilización, deben ser pensadas especialmente desde las nociones de autocentramiento. No solo hay el ámbito estratégico nacional. Hay otros ámbitos estratégicos, desde lo local hasta lo global. En esta aproximación las dimensiones locales quedan muy bien situadas. Esto implica una estrategia de organización de la política y de la economía que se construye desde abajo y desde dentro, desde lo comunitario y solidario; en donde, por ejemplo, cobran fuerza aquellas propuestas productivas que surgen desde el seno de los barrios y de las comunidades campesinas.

Realizar el autocentramiento implica decisiones políticas colectivas que pueden darse siguiendo un camino gradual, empezando desde abajo: desde la región o regiones con relación al país y luego del país con respecto al mercado mundial. Este empeño

${ }^{15}$ Pierre Rabhi (2013). Hacia la sobriedad feliz, Madrid, Errata Naturae.

${ }^{16}$ Es recomendable el libro de Harald Bender, Norbert Bernholt y Bernd Winkelmann (2012). Kapitalismus und dann? Systemwandel und Perspektiven gesellschaftlicher Transformation. La economía solidaria es motivo de preocupación y razón para el impulso a proyectos concretos en muchos lugares del planeta. Francia, Brasil, Ecuador, Italia, España, etc. Véase al respecto los trabajos de Jean-Lous Laville, Paul Singer, Luiz Inácio Gaiger, José Luis Coraggio (2012) y por supuesto de Luis Razzeto, uno de los mayores estudiosos y propulsores de este asunto. En España se han recopilado una serie de acciones concretas destinadas a construir otra economía desde la vida cotidiana: Alternativas Económicas 33-Alternativas para vivir de otra manera (2014). 
será mucho más fácil si se cuenta con el respaldo del gobierno central y también si hay una estrategia de integración regional autónoma, es decir que no esté normada por las demandas del capital transnacional. ${ }^{17}$

El fundamento básico de la vía autocentrada es el desarrollo de las fuerzas productivas endógenas, incluyendo capacidades humanas y recursos productivos locales y el correspondiente control de la acumulación y centramiento de los patrones de consumo. Todo esto debe venir acompañado de un proceso político de participación plena, de tal manera que (sobre todo en los países en donde el gobierno central no está sintonizado con esta visión) se construyan "contrapoderes" (económico y político) que puedan impulsar paulatinamente las transformaciones a nivel del país.

Esto implica ir gestando, desde lo local, espacios de poder real en lo político, en lo económico y en lo cultural. A partir de ellos se podrán forjar los embriones de una nueva institucionalidad estatal, así como también diseñar y construir una renovada lógica de mercado, en el marco de una nueva convivencia social. Estos núcleos de acción servirán de base para la estrategia colectiva que debe construir un proyecto de vida en común, que no podrá ser una visión abstracta que descuide a los sujetos y a las relaciones presentes, reconociéndolos tal como son hoy y no como queremos que sean mañana.

Una propuesta de transición desde el autocentramiento - desde el punto de vista económico- prioriza el mercado interno. Esto, sin embargo, no significa, por ejemplo, volver al modelo de "sustitución de importaciones" de antaño, que procuró beneficiar y de hecho favoreció a los capitalistas locales, con la expectativa de fomentar o fortalecer una inexistente "burguesía nacional". En el marco del autocentramiento, el mercado interno quiere decir mercados heterogéneos y diversos, así como también mercado de masas. En este último predominará el vivir con lo nuestro y para los nuestros, vinculando al campo con la ciudad, lo rural y lo urbano, para desde allí evaluar las posibilidades de reinsertarse en la economía mundial, definiendo en qué campos es conveniente hacerlo. ${ }^{18}$

No es posible desarrollar proyectos económicos alternativos, sin involucrar activamente a la población en el diseño y gestión de los mismos. Simultáneamente es necesario fomentar la creación y fortalecimiento de unidades de producción autogestionarias,

${ }^{17}$ Como sucede con los ejes multimodales previstos en el IIRSA: "Iniciativa para la Integración de la Infraestructura Regional Sudamericana", que constituye un proyecto para vincular aún más a la región a las demandas de acumulación del capitalismo global.

${ }^{18}$ En este punto, aunque parezca curioso si estamos hablando del Buen Vivir, convendría recuperar la recomendación de John Maynard Keynes (1933): "Yo simpatizo, por lo tanto, con aquellos quienes minimizarían, antes que con quienes maximizarían, el enredo económico entre naciones. Ideas, conocimiento, ciencia, hospitalidad, viajes - esas son las cosas que por su naturaleza deberían ser internacionales - Pero dejen que los bienes sean producidos localmente siempre y cuando sea razonable y convenientemente posible, y, sobre todo, dejemos que las finanzas sean primordialmente nacionales". (“Autosuficiencia Nacional”, Revista Ecuador Debate (60), CAAP, Quito, diciembre 2003.) 
asociativas, cooperativas o comunitarias (desde las familias, pasando por las "microempresas" a nivel local, hasta llegar a los proyectos regionales). Esta propuesta exige imperiosamente el fortalecimiento de estos espacios comunitarios. Así, para mencionar un ejemplo, los productores agrícolas deberían formar asociaciones que les permitan manejar temas clave de manera conjunta, como son el procesamiento comunitario de sus productos, el acceso también comunitario a mercados, así como a los créditos, las tecnologías, la capacitación, entre otras.

Hay que crear, por igual, las condiciones para propiciar la producción de (nuevos) bienes y servicios, sobre la base de tecnologías adaptadas y autóctonas. Esta política debe favorecer a empresas colectivas, familiares o incluso individuales, pero sin dar paso al surgimiento y consolidación de estructuras oligopólicas y menos aún monopólicas. Estos bienes y servicios deben estar acordes con las necesidades axiológicas y existenciales ${ }^{19}$ de los propios actores del cambio, a fin de estimular el aprendizaje directo, la difusión y el uso pleno de las habilidades, la motivación para la comprensión de los fenómenos y para la creación autónoma.

En lo social la transición propone la revalorización de las identidades culturales y el criterio autónomo de las poblaciones locales, la interacción e integración entre movimientos populares y la incorporación económica y social de las poblaciones. Estas deben dejar su papel pasivo en el uso de bienes y servicios colectivos y convertirse en propulsoras autónomas de los servicios de salud, educación, transporte, entre otros, nuevamente impulsados coordinada y consensuadamente desde la escala local-regional.

Estos procesos demandan el cambio de los patrones tecnológicos para recuperar e incentivar alternativas locales, sin negar los valiosos aportes tecnológicos que pueden provenir del exterior, especialmente de las llamadas tecnologías intermedias y limpias. Hay que entender que gran parte de las capacidades y conocimientos locales están en manos de comunidades y pueblos dentro de nuestros países, que por decisión, por tradición o por marginación, se han mantenido fuera del patrón tecnológico occidental. En estos segmentos del aparato productivo, muchas veces marginalizados, se utilizan e inventan opciones para facilitar el trabajo productivo y el consumo de productos locales, artesanales y orgánicos.

Muchas prácticas tradicionales tienen tal grado de solidez, que el paso del tiempo parecería solo afectarlas en lo accesorio y no en lo profundo. Además, si se observa con detenimiento hay respuestas productivas, como son las existentes en la agricultura orgánica, que tienen mejores rendimientos económicos en términos amplios que

${ }^{19}$ Manfred Max Neef, Antonio Elizalde y Martín Hopenhayn (1986) nos recuerdan que las necesidades no son infinitas y relativas, sino que son finitas y universales. Ellos nos proponen una matriz que abarca nueve necesidades humanas básicas axiológicas: subsistencia, protección, afecto, comprensión, participación, creación, recreo, identidad y libertad; y, cuatro columnas con las necesidades existenciales: ser, tener, hacer y estar. Ver Desarrollo a Escala Humana una opción para el futuro, Centro de Alternativas de Desarrollo. 
las promocionadas actividades convencionales. La construcción de un nuevo patrón tecnológico demanda rescatar, desarrollar, o adaptar nuevas y viejas tecnologías, que para ser liberadoras no deberán generar nuevos modelos de dependencia (a través de los transgénicos, por ejemplo), deberán ser de libre circulación y de bajo consumo de energía, así como de reducidas emisiones de $\mathrm{CO}_{2}$, muy poco contaminantes, al tiempo que aseguran la creación de abundantes puestos de trabajo de calidad.

Lo interesante en este momento es reconocer que nadie tiene una receta concluida de cómo hacerlo. Eso, lejos de ser un motivo de preocupación, debe alentarnos. Solo entre todos y todas podremos encontrar las alternativas necesarias. La lista de proyectos e iniciativas exitosas, sustentadas sobre las bases de una economía solidaria y sustentable, a lo largo del planeta, es enorme. Hay que abrir todos los espacios y canales posibles para difundir estas propuestas, así como los procesos puestos en marcha y los resultados obtenidos.

Es indispensable tener presente que un proyecto de organización social y productiva, sustentado en la dignidad y la armonía, en tanto propuesta emancipadora, demanda una revisión del estilo de vida vigente, sobre todo a nivel de las élites y que sirve de marco orientador (inalcanzable) para la mayoría de la población en el planeta. Igualmente habrá que procesar, sobre cimientos de equidades reales, la reducción del tiempo de trabajo y su redistribución, así como la redefinición colectiva de las necesidades axiológicas y existenciales del ser humano en función de satisfactores singulares y sinérgicos ${ }^{20}$ ajustados a las disponibilidades de la economía y la Naturaleza.

Más temprano que tarde, tendrá que darse prioridad a una situación de suficiencia, en tanto se busque lo que sea bastante en función de lo que realmente se necesita, antes que una siempre mayor eficiencia sostenida sobre bases de una incontrolada competitividad y un desbocado consumismo, que ponen en riesgo las bases mismas de la sociedad y de la sustentabilidad ambiental. Este proyecto de vida - Buen Vivir - no es sinónimo de opulencia y tampoco puede darse a costa del mal vivir de nadie.

Esta transición económica, por cierto, debería hacerse extensiva a todas aquellas formas de producción, como la extractiva, que sostienen las bases materiales del capitalismo y que ponen en riesgo la vida misma. Los países productores y exportadores de materias primas, es decir de Naturaleza, insertos como tales sumisamente en el mercado mundial, son funcionales al sistema de acumulación capitalista global y son también indirecta o aun directamente causantes de los problemas ambientales globales.

Finalmente, en lo político, tales procesos contribuirían a la conformación y fortalecimiento de instituciones representativas y al desarrollo de una cultura democrática y de participación. En este sentido habrá que fortalecer los procesos asamblearios propios de los espacios comunitarios.

\footnotetext{
${ }^{20}$ Ver Manfred Max-Neef, Antonio Elizalde y Martin Hopenhayn (1986).
} 


\section{Al rescate o construcción de otras lógicas económicas}

En esta otra economía, el punto de partida es el ser humano. Así él debe ser el centro de la atención y es su factor fundamental, pero siempre integrado como parte de la Naturaleza.

Si el ser humano es el eje de esta otra economía, el trabajo es su sostén. Esto plantea el reconocimiento en igualdad de condiciones de todas las formas de trabajo, productivo y reproductivo. El mundo del trabajo forma parte fundamental de la economía solidaria, entendida también como "la economía del trabajo" (Coraggio 2011).

El trabajo, entonces, es un derecho y un deber social. Por lo tanto ninguna forma de desempleo o subempleo puede ser tolerada. No se trata simplemente de producir más, sino de producir para vivir bien. Puestas las cosas en su debido orden, el trabajo contribuirá a la dignificación de la persona. Habrá que asumir al trabajo como espacio de libertad y de goce. Y en este contexto, tal como se anotó antes, habrá incluso que pensar también en un proceso de distribución del trabajo, que cada vez es más escaso; proceso que vendrá atado, por cierto, con una nueva forma de organizar la economía y la sociedad misma.

Por igual habrá que fortalecer los esquemas de auto y cogestión en todo tipo de empresas, para que los trabajadores y las trabajadoras decidan en la conducción de sus diversas unidades productivas.

Para empezar una acción transformadora hay que reconocer que en las economías capitalistas lo popular y solidario convive y compite con la economía capitalista y con la economía pública.

Este sector está compuesto por el conjunto de formas de organización económicasocial en las que sus integrantes, colectiva o individualmente, desarrollan procesos de producción, intercambio, comercialización, financiamiento y consumo de bienes y servicios. Estas formas de organización económica solidaria incluyen en el sector productivo y comercial, así como diversos tipos de unidades económicas populares. A estas se suman las organizaciones del sector financiero popular y solidario, que tienen a las cooperativas de ahorro y crédito como uno de sus principales pilares, así como a las cajas solidarias y de ahorro y los bancos comunales. Inclusive habría que rescatar valiosas experiencias con dineros alternativos, controlados por las comunidades, que han servido no solo para resolver problemas en épocas de crisis agudas, sino que han sido de enorme utilidad para descubrir y potenciar las capacidades locales existentes.

Estas organizaciones sustentan (no siempre) sus actividades en relaciones de solidaridad, cooperación y reciprocidad y ubican al ser humano como sujeto y fin de toda actividad económica por sobre el lucro, la competencia y la acumulación de capital. Desde esa lógica económica se debe romper con toda forma de paternalismo, asistencialismo o clientelismo, por un lado, y por otro, con toda forma de concentración y acaparamiento; prácticas que han dominado la historia de la región: migajas para el pueblo y la gran torta para las minorías. 
Aquí lo que cuenta, además, es que el ser humano debe vivir en armonía con la Naturaleza, buscando, individual y comunitariamente, la construcción de una vida sustentable en dignidad.

El Estado tiene mucho que hacer en este campo. Por ejemplo, invertir en infraestructura y generar las condiciones que dinamicen a los pequeños y medianos productores, reconociendo que son grupos con una enorme productividad del capital. Un pequeño productor con una pequeña inversión le saca mucho más rédito a la unidad monetaria invertida que la unidad monetaria que invierten los grandes grupos de capital. El problema de ese pequeño productor es que no tiene capacidad de acumular. Gana muy poco y vive en condiciones de inmediatez económica, subordinado muchas veces al gran capital. Con frecuencia tampoco tiene una adecuada preparación profesional y formación técnica, dado que el Estado no se ha preocupado en materia de capacitación para la adecuada gestión de este sector productivo.

Igualmente, hay que favorecer la cooperación de estas empresas de propiedad social, en lo que se denominan "distritos industriales populares". Experiencias existen en muchas partes. Lo que toca es profundizar y ampliar este tipo de prácticas, para que cada vez más empresas compartan costos fijos (maquinaria, edificios, equipo, tecnologías, entre otros) y aprovechen así economías de escala, lo que les aseguraría una mayor productividad. (Supervisando, por cierto, que se produzca sin afectar al ambiente o sobre la base de la explotación inmisericorde de la mano de obra.)

Por ello se vuelve impostergable una reconversión de la matriz productiva. Esta decisión, en los países productores y exportadores de materias primas exige el ejercicio soberano sobre la economía, la desprimarización de su estructura, el fomento y la inversión para la innovación científico-tecnológica estrechamente vinculada al nuevo aparato productivo (y no en guetos de sabios), la inclusión social, la capacitación laboral y la generación de empleo abundante y bien remunerado. Este último punto es crucial para evitar el subempleo, la desigual distribución del ingreso, el desangre demográfico que representa la migración, entre otras patologías inherentes al actual modelo primario-exportador de acumulación.

De eso se trata cuando se plantean estrategias de transición que tendrán que ser necesariamente plurales. Teniendo como horizonte la vocación utópica de futuro hay que desplegar acciones concretas para resolver problemas concretos. Y en ese empeño hay que nutrirse de todos los aportes que apunten en dicha dirección, rescatando y potenciando las prácticas y los saberes ancestrales, así como todas aquellas visiones y vivencias sintonizadas con la praxis de la vida armónica y de la vida en plenitud. Lo que interesa es potenciarlas, multiplicarlas y difundirlas.

Otro punto fundamental radica en el reconocimiento que esta nueva economía no puede circunscribirse al mundo rural o a los sectores populares urbanos marginados. Uno de los mayores desafíos radica en pensar formas diferentes de organizar la vida para y desde las ciudades, en donde la sustentabilidad está casi siempre ausente y en 
donde muchas veces los niveles de competencia salvaje son mayores que en el campo. La tarea pasa por repensar las ciudades, rediseñarlas y reorganizarlas, al tiempo que se construyen otras relaciones con el mundo rural.

De todo lo anterior podemos concluir en la necesidad de dar paso a los siguientes aspectos:

» Precisamos desarmar "la religión del crecimiento económico". Es evidente que el crecimiento económico no puede ser el objetivo de una economía. Es más, para algunos menesteres puede incluso resultar contraproducente. Si ya se acepta que el crecimiento económico no es equivalente a desarrollo, con mayor razón eso debe ser válido para la construcción del Buen Vivir o Sumak Kawsay. Incluso aquí se podría analizar si hay un crecimiento bueno y otro malo; pero, en esencia, se debe aceptar que el crecimiento económico permanente en un mundo finito es una locura.

» La desmercantilización de la Naturaleza, como parte de un reencuentro consciente con la Pachamama, es un asunto crucial. Los objetivos económicos deben estar subordinados a las leyes de funcionamiento de los sistemas naturales, sin perder de vista el respeto a la dignidad humana y procurando asegurar calidad en la vida de las personas. Claro y sin rodeos, la economía debe subordinarse a la ecología. La desmercantilización de la Naturaleza vendrá de la mano de la desmaterialización de los procesos productivos, orientada a una producción más eficiente, capaz de utilizar menos recursos.

Si hablamos de desmercantilización de la Naturaleza debemos hacerlo también para los bienes comunes, entendidos como aquellos bienes que pertenecen o son de usufructo o son consumidos por un grupo más o menos extenso de individuos o por la sociedad en su conjunto. Estos bienes pueden ser sistemas naturales o sociales, palpables o intangibles (Wikipedia, por ejemplo), distintos entre sí, pero comunes al ser heredados o construidos colectivamente.

» La descentralización es otro de los aspectos medulares de una nueva economía. En muchos ámbitos, como el de la soberanía alimentaria o energética, por ejemplo, se precisan respuestas-acciones más cercanas a la gente. Es decir desde las comunidades habrá que encontrar las respuestas más adecuadas. Está acción está orientada a recuperar el protagonismo y el control de las personas, es decir de las comunidades, en la toma de decisiones, fortaleciendo la participación y los procesos locales.

» La distribución equitativa del ingreso y la redistribución de la riqueza es un paso fundamental para el Buen Vivir. Si la economía debe subordinarse a los mandatos de la Tierra, el capital tiene que estar sometido a las demandas de la sociedad humana, que no solo es parte de la Naturaleza, sino que es Naturaleza. Esto exige dar paso a esquemas de profunda redistribución de la riqueza y del poder, así como de construcción de sociedades fundamentadas en equidades en plural. No solo está en juego la cuestión de la lucha de clases, es decir el enfren- 
tamiento capital-trabajo. Está en juego la superación efectiva del concepto de "raza" en tanto elemento configurador de las sociedades dependientes, en donde el racismo es una de sus manifestaciones más crudas. Es tarea fundamental y urgente la superación del patriarcado y del machismo.

» La democratización de la economía completa lo anotado anteriormente. Es indispensable que la toma de decisiones en el ámbito económico, en todos los niveles, sea cada vez más participativa y deliberativa. Esto implica asegurar tanto los derechos de los productores como de los consumidores. Deben regir principios de organización social que vayan más allá de lo crematístico y del utilitarismo convencional.

En síntesis, una visión que supere el fetiche del crecimiento económico, que propicie la desmercantilización, la descentralización, la redistribución de la riqueza y del poder son bases para una estrategia de construcción colectiva de otra economía, indispensable para el Buen Vivir o Sumak Kawsay.

\section{Un penúltimo punto: construcción paciente, no improvisación irresponsable}

Tengamos presente que la Humanidad no es una comunidad de seres agresivos y brutalmente competitivos. Muchos de estos no-valores han sido creados e incluso exacerbados por una civilización como la capitalista que ha favorecido el individualismo, el consumismo y la acumulación agresiva de bienes materiales. Científicamente se ha demostrado la tendencia natural dominante de los humanos y los animales superiores a la cooperación y la asistencia mutua.

Entonces, de lo que se trata es de recuperar y fortalecer esos valores y esas instituciones sustentadas en la reciprocidad y solidaridad. Esta tarea empieza en el hogar y en los centros de aprendizaje primario, así como en las diversas instancias de la vida de los seres humanos. No se trata de acciones caritativas en medio de un ambiente de creciente competencia. Lo que se quiere es desarmar ese mundo orientado y conminado a la competencia, para reorientarlo hacia la solidaridad y la sustentabilidad.

En esta línea de reflexión, hay que valorar los postulados feministas de una economía orientada al cuidado de la vida, basada en la cooperación, complementariedad, reciprocidad y solidaridad. Estas concepciones son relevantes para las mujeres y para la sociedad en su conjunto, como parte de un proceso de construcción colectiva de una nueva forma de organizar la vida. Exigen nuevos acercamientos feministas en donde se diluciden y se cristalicen los conceptos de autonomía, soberanía, dependencia, reciprocidad y equidad. 
En los países del Sur global, sobre todo, la soberanía aflora con fuerza, en donde hay varios ámbitos para la acción, como el monetario, el financiero, el energético o el alimentario, para mencionar algunos de ellos.

Sin pretender agotar el tema de las soberanías, debe quedar absolutamente claro que la soberanía alimentaria será un pilar fundamental de otra economía, que se sustentará en el derecho que tienen los agricultores a controlar la agricultura y los consumidores a controlar su alimentación. Por lo tanto la atención debe estar dirigida a dar a la alimentación el trato de derecho humano de todo ciudadano y ciudadana. Y esto empieza por erradicar el hambre a través de una verdadera revolución agraria que incorpore los ya mencionados derechos de los productores y de los consumidores.

El acceso democrático a la tierra — que es un bien público — es un eje central de la soberanía alimentaria. Esta estrategia demanda respuestas participativas, no burocratizadas; descentralización efectiva, no centralización absorbente; reconocimiento de tecnologías propias y ancestrales, no su marginación. Los campesinos y sus familias serán los actores centrales de este proceso, sobre todo a través de asociaciones de productores, comercializadores y procesadores de alimentos.

Tanto el gobierno central como los gobiernos descentralizados deben establecer las políticas adecuadas para fomentar el cultivo ético de la tierra, desprivatizar el agua asegurando la gestión social del riego, establecer adecuados mecanismos de crédito, impulsar tecnologías apropiadas con el medio, fomentar los sistemas de transporte y los mercados justos, promover la reforestación y cuidar de cuencas hidrográficas mediante tecnologías apropiadas, apoyar los procesos de capacitación de los campesinos, alentar el establecimiento de industrias locales para procesar los productos agrícolas.

Todo lo expuesto brevemente demanda una política de aprovechamiento de los recursos naturales orientada por la siguiente consigna: transformar antes que transportar, tanto para productos tradicionales de exportación como para la producción de consumo interno.

Es fundamental proteger el patrimonio genético, tanto como impedir el ingreso de semillas y cultivos transgénicos para evitar la pérdida de diversidad genética en la agricultura, la contaminación de variedades tradicionales y la aparición de súper plagas y súper malezas. Y por supuesto no se puede tolerar la producción de alimentos para alimentar automóviles y no seres humanos, me refiero a los bio o agrocombustibles.

Las finanzas deben cumplir un papel de apoyo al aparato productivo y no ser más simples instrumentos de acumulación y concentración de la riqueza en pocas manos; realidad que alienta la especulación financiera. Se precisa la construcción de una nueva arquitectura financiera, en donde los servicios financieros sean de orden público. Allí las finanzas populares, por ejemplo las cooperativas de ahorro y crédito, deben asumir un papel cada vez más preponderante como promotoras del desarrollo, en paralelo con una banca pública de fomento, como aglutinadora del ahorro interno e impulsadora de economías productivas de características más solidarias. Las instituciones financieras 
privadas deberán dejar su espacio de predominio a favor de este otro tipo de estructura financiera popular y pública.

Esta nueva economía consolida el principio del monopolio público sobre los recursos estratégicos, pero a su vez establece una dinámica de uso y aprovechamiento de esos recursos desde una óptica sustentable. Por igual son necesarios mecanismos de regulación y control en la prestación de los servicios públicos desde la sociedad. Se precisa que la propiedad — privada, comunitaria, pública o estatal — cumpla su función social, tanto como su función ambiental.

Los planteamientos expuestos brevemente, que no abordan todos los ámbitos desde donde se debe trabajar esta nueva economía, marcan un derrotero por donde debería marchar la construcción de una nueva forma de organización y de economía. Quizás convenga rescatar aquí, para concluir estas pocas líneas, como principio rector de este proceso de transición el postulado de Carlos Marx en su crítica al programa de Gotha (1875): "de cada cual, según sus capacidades; a cada cual, según sus necesidades". Y todo esto aceptando que los seres humanos formamos parte de la Naturaleza.

Estas son palabras que huelen a utopía. De eso mismo se trata. Hay que escribir todos los borradores posibles de una utopía por construir. Una utopía que implica la crítica de la realidad desde los principios plasmados en la filosofía de la vida plena. Una utopía que, al ser un proyecto de vida solidario y sustentable, nos dice lo que debe ser: una opción alternativa colectivamente imaginada, políticamente conquistada y construida, a ser ejecutada por acciones democráticas, en todo momento y circunstancia.

En consecuencia, si el Buen Vivir o Sumak Kawsay abre la puerta para transitar hacia una nueva civilización, se precisa otra economía. Esta no surgirá de la noche a la mañana y menos aún de la mano de caudillos iluminados. Se trata de una construcción paciente y decidida en desmontar varios fetiches y en propiciar cambios radicales.

De lo expuesto se puede concluir que el Buen Vivir se aparta de las ideas occidentales convencionales del progreso, y apunta hacia otra concepción de la vida, otorgando una especial atención a la Naturaleza, sin descuidar para nada el tema de las equidades sociales y culturales.

Queda en claro, por lo tanto, que el Buen Vivir es un concepto plural (mejor sería hablar de "buenos vivires" o "buenos convivires") que surge especialmente de las comunidades indígenas, sin negar las ventajas tecnológicas del mundo moderno o posibles aportes desde otras culturas y saberes que cuestionan distintos presupuestos de la modernidad dominante. Como plantean los zapatistas, la tarea es construir un mundo donde caben todos los mundos, sin que nadie viva mal para que otro viva mejor.

En síntesis, esta compleja tarea implica aprender desaprendiendo, aprender y reaprender al mismo tiempo. Una tarea que exigirá cada vez más democracia, cada vez más participación y siempre sobre bases de mucho respeto. Nadie puede asumirse como propietario de la verdad. 


\section{Bibliografía}

Acosta, A. (2013): El Buen Vivir - Sumak Kawsay, una oportunidad para imaginar otros mundos, Barcelona, Icaria.

Acosta, A. (2013): Otra economía para otra civilización; Temas № 75, La Habana, Cuba. pp. 21-27.

AcostA, A. et al. (2011): "Extractivismo y neoextractivismo: Dos caras de la misma maldición”, en VV.AA, Más allá del desarrollo, Quito, Fundación Rosa Luxemburg.

Acosta, A. (2011): "Los Derechos de la Naturaleza - Una lectura sobre el derecho a la existencia”, en Alberto Acosta y Esperanza Martínez, eds., La Naturaleza con Derechos - De la filosofía a la política, Quito, Serie debate constituyente Abya-Yala.

AcostA, A. (2010):“El Buen Vivir en el camino del post-desarrollo - Una lectura desde la Constitución de Montecristi”, Policy Paper, 9, Fundación Friedrich Ebert. Disponible en:

$<$ http://library.fes.de/pdf-files/bueros/quito/07671.pdf $>$ [Consulta: 14 de febrero de 2014].

Altvater, E. (2004): "La ecología de la economía global”, en La Globalización: La euforia llegó a su fin", Foros Ecología y Política, 2, Quito, Abya-Yala.

Coraggio, J.L. (2011): "Economía social y solidaria” en Acosta, Alberto y Esperanza Martínez (eds.), El trabajo antes que el capital, Quito, Serie Debate Constituyente, Abya-Yala.

DÁvalos, P. (2008): “El “Sumak Kawsay” ("Buen vivir”) y las cesuras del desarrollo”. Disponible en:

$<$ http://signisalc.org/redes/teologia/files/2009/10/pablo-davalos-2008-sumak-kawsayy-las-cesuras-del-desarrollo.pdf $>$ [Consulta: 12 de diciembre de 2013]

ESTERMANN, J. (2014): “Ecosofía andina - Un paradigma alternativo de convivencia cósmica y de vida plena, en Bifurcación del Buen Vivir y el Sumak Kawsay, Quito, Ediciones SUMAK.

EcheverríA, B. (2010): Modernidad y Blanquitud, México, Editorial ERA.

De Souza Silva, J. (2010): Hacia el Día Después del Desarrollo’ Descolonizar la comunicación y la educación para construir comunidades felices con modos de vida sostenibles, ALER, (mimeo).

GudynAs, E. (2009): “El mandato ecológico”, en Acosta Alberto y Esperanza Martínez, (eds.), Derechos de la naturaleza y políticas ambientales en la nueva Constitución, Quito, Serie Debate Constituyente, Abya-Yala.

GuDYNAS, E. (2014): “Izquierda y progresismo: la gran divergencia”, Disponible en: $<$ http://www.rebelion.org/noticia.php?id=17865> [Consulta: 14 de febrero de 2015] 
Gudynas, E. y A. Acosta (2011): "La medición del progreso y del bienestar - Propuestas desde América Latina", en Rojas, Mariano (coord.), El buen vivir o la disolución de la idea del progreso, México, Foro Consultivo Científico y Tecnológico de México.

GudynAs, E. y A. AcosTA (2011):“La renovación de la crítica al desarrollo y el buen vivir como alternativa", Utopia y Praxis Latinoamericana, Revista Internacional de Filosofía Iberoamericana y Teoría Social, Centro de Estudios Sociológicos y Antropológicos (CESA), Facultad de Ciencias Económicas y Sociales, Universidad del Zulia-Venezuela (53).

GudynAs, E. (2014): "Buen Vivir: sobre secuestros, domesticaciones, rescates y alternativas"; en Bifurcación del Buen Vivir y el Sumak Kawsay, Quito, Ediciones SUMAK.

Hidalgo-Capitán, A.L., A. Guillén y N. Deleg (2014): Antología del Pensamiento Indigenista Ecuatoriano sobre Sumak Kawsay, Universidad de Cuenca y Universidad de Huelva.

HoutART, F. (2011a): El camino a la Utopía y el bien común de la Humanidad, La Paz, Ruth Casa Editorial.

HoutART, F. (2011b): "El concepto del Sumak Kawsay (Buen Vivir) y su correspondencia con el bien común de la humanidad", Revista Ecuador Debate, 84.

Latouche, S. (2008): La apuesta por el decrecimiento - ¿Cómo salir del imaginario dominante,? Barcelona, Icaria.

Latouch, S. (2009): Pequeño tratado del decrecimiento sereno, Barcelona, Icaria.

LEFF, E. (1985): Ecología y capital: racionalidad ambiental, democracia participativa y desarrollo sustentable, México, Siglo XXI Editores.

LEFF, E. (2004): Racionalidad ambiental: la reapropiación social de la naturaleza, México, Siglo XXI Editores.

LefF, E. (2008): “Decrecimiento o deconstrucción de la economía”, Peripecias, 117.

NAREDo, J.M. (2000): Luces en el laberinto - Autobiografía intelectual, Madrid, editorial La Catarata.

Oviedo Freire, A. (2011): Qué es el sumakawsay - Más allá del socialismo y capitalismo, Quito.

Quijano, A. (2000): "El fantasma del desarrollo en América Latina", en Acosta, Alberto (compilador), El desarrollo en la globalización - El resto de América Latina, Caracas, Nueva Sociedad e ILDIS.

Quijano, A. (2011): “Bien vivir?: entre el "desarrollo la descolonialidad del poder”, Revista Ecuador Debate, 84.

Quisano, A. (2001): "Globalización, colonialidad del poder y democracia", en Tendencias básicas de nuestra época: globalización y democracia, Caracas, Instituto de Altos Estudios Diplomáticos Pedro Gual, Ministerio de Relaciones Exteriores. 
RabHI, P. (2013): Hacia la sobriedad feliz, Madrid, Errata Naturae.

Shiva, V. (2009): "La civilización de la selva", en Acosta, Alberto y Esperanza Martínez (eds.), Derechos de la Naturaleza - El futuro es ahora, Quito, Abya Yala.

Schuldt, J. (2012): Desarrollo a Escala Humana y de la Naturaleza, Lima, Universidad del Pacífico.

TORTOSA, J.M. (2011): “Mal desarrollo y mal vivir”, en Pobreza y violencia escala mundial, en Alberto Acosta y Esperanza Martínez (eds.), Quito, Serie Debate Constituyente, Abya-Yala.

Tortosa, J.M. (2009): Sumak Kawsay, Suma Kamaña, Buen Vivir, Madrid, Fundación Carolina.

Unceta, K. (2014): Desarrollo, postcrecimiento y Buen Vivir, en Acosta, Alberto y Esperanza Martínez (eds.), Serie Debate Constituyente, Quito, Abya-Yala.

VACACELA QuishPe, R.C. (2007): Sumac Cusai - Vida en armonía, Quito, Instituto Quichua de Biotecnología Sacha Supai.

Viteri Gualinga, C. (2000): "Visión indígena del desarrollo en la Amazonía", Quito, (mimeo). 